should begin at this point, by asking what is meant by the sharing of research results. It is not necessary to wait for SDI to be complete to make a start. The place at which to begin is that essential component of SDI, as described in the United States a system of satellites carrying infrared sensors to detect missiles in the early stages of their flight, but surveillance satellites, also important sources of data for the verification of last week's treaty, will be essential for monitoring performance under its strategic successor. So why not begin right away, by negotiating an agreement on "sharing" of surveillance technology, present and future? To those most concerned, this may seem an outrageous suggestion, given that the resolution achieved by surveillance satellites is one of the most closely guarded of military secrets. "We do not want the other fellow to know what we can see" is the usual argument. But that position must now have been seriously undermined by the mere exchange of information required for last week's treaty. Moreover, the present regime will be the more stable if each party to the INF treaty knows that the other is well-equipped to know that it is keeping to the rules. That is one reason why an early negotiation on surveillance would be a useful prelude to what must follow; even a failure to make progress would be a useful warning of troubles that may lie ahead.

More generally, the undertaking that negotiations will precede deployment is politically important. It is not merely that President Reagan may have more to fear from Mrs Thatcher's tongue than even from Mr Gorbachev's, but that Western European governments are likely to regard compliance with the undertaking as an important determinant of their future relationships with the major powers. Senators who hold that Western Europe would be better able to make that demand if it shouldered more responsibility for its own defence will be missing the important point. (But the INF treaty will stimulate close attention to the modernization of conventional forces, while this week's discussions in London between British and French ministers on the joint development of air-launched missiles is another sign of the way the wind is blowing.) The general enthusiasm for last week's treaty should not conceal the diversity of the reasons for rejoicing.

That the parties to arms control agreements (five Western European governments have formally accepted that the Soviet Union has a right to monitor the removal of US missiles) may have different motives is by no means unusual. Especially to mainland Europeans, one of the still-distant prizes of the arms control process is that Central Europe may thereby become more like the politically free and culturally rich place it used to be, but without the recurrent conflicts that made Europe unsafe as well. It seems now to be generally understood, perhaps in the East as well, that this happy state of affairs will not be possible until the issues that divide people are the sufficiently contentious quarrels that arise over trade, broadcasting and competitive sport. Sensible Europeans acknowledge that there is a long way to go before that will be the case, but they also fear that superpower tension over the deployment of SDI could make their legitimate goal less easily attainable.

None of this is meant to rubbish last week's negotiations. Both the major powers have earned credit by their demeanour and even by their evident realism about the difficulties they face. But the danger is that they may not fully appreciate that the effect of INF is not simply to put the clock back to say 1975 , before détente began to unravel. Western Europe is stronger economically, yet Japan (spending one per cent of GNP on defence) is the engine of the world's economy. By the same tests, both the major powers have faltered, the United States only in a relative sense but the Soviet Union to such a degree that the state of the Soviet economy appears to be the mainspring of the new drive for change, almost without regard to where it may lead. Two lessons can be drawn from that. First, history will not of its own accord repeat itself, meaning that the strategic agreement will not follow INF as, in the 1970s, SALT II followed SALT I.
Second, the economic benefits of military restraint, long understood by middle and small powers, have now become respectable prizes for the superpowers. It will be interesting to see how quickly President Reagan follows Mr Gorbachev in heeding that truth.

\section{Who pays for health?}

\section{British health services are heading for another crisis; they need a public policy.}

THE British National Health Service, known in some quarters as "socialized medicine", is a splendid institution once again in trouble. For the past several months, the newspapers have been full of tales of how urgently necessary surgery has been postponed for lack of skilled people, or of the funds with which to employ them. Last week, the presidents of the three principal colleges of medicine (physicians, surgeons and obstetricians) startled the government (and probably some of their own members as well) by issuing a public statement that the Health Service is urgently in need of more resources or in danger of collapse. The government's reply is that spending on the health services is indeed increasing, by roughly $£ 1,000$ million a year, and will continue to increase for the foreseeable future. Yet so will the gap between expectation and reality.

The nature of the problem is familiar, not only in Britain (West Germany and the United States have institutionalized different resolutions of the same dilemma) nor only in the provision of health services (British education has been squeezed for similar reasons). Public services, as the British National Health Service remains, are notoriously always under financial pressure from rising expectations. Health services are especially vulnerable, for expectations rise to encompass immortality. The British problem is especially acute because the national wealth has been growing less quickly than the standard of medical treatment elsewhere, not to mention spending; US health costs are now nearly 11 per cent of gross national product (GNP), compared with 8 per cent of a smaller (GNP) in Britain (amounting to roughly $£ 400$ per head a year). The present government, while committed to the maintenance of the National Health Service (if not from conviction, then for sound political reasons, the wish not to offend too many voters), seems to be hoping for some kind of undefined collaboration with the private sector, largely that supported by medical insurance schemes.

That is potentially too risky a way of going forward. While there are few other countries in which private medicine is entirely out of court (even the Soviet Union has a little) there appears to be none in which it is in roughly equipotent balance with the public services. Nor is stability likely in a thoroughly mixed system. To the extent that insurance-based medicine may be financed at somewhat arbitrary levels, private medicine is likely always to be able to draw scarce resources, mostly people, from the public sector. In Britain, that appears to account for the present shortage of specialized nurses in the public sector. The real danger is that a continuation of this trend could hamper the capacity of the public service to perform its notable civilizing services - the care of the old, the young, the indigent and the chronically sick.

That is why almost any policy would be preferable to the present pragmatism. The government's encouragement of private medical insurance (premiums nevertheless do not earn tax relief, as in the United States) may ease its budget problem, but in the long run will increase unit costs for medical services. If that is the route that is to be followed, compulsory medical insurance (as in West Germany) for those at work would be preferable. But in the short run, there seems no alternative to extra public spending. The British government, with a budget only a few months away, would prefer to cut taxes, which might well be the less popular course. 